\title{
Brain morphometry and the neurobiology of levodopa-induced dyskinesias: current knowledge and future potential for translational pre-clinical neuroimaging studies
}

\author{
Clare J. Finlay ${ }^{1}$, Susan Duty ${ }^{1}$ and Anthony C. Vernon ${ }^{2}$ * \\ ${ }^{1}$ Wolfson Centre for Age-related Diseases, King's College London, London, UK \\ ${ }^{2}$ Department of Neuroscience, James Black Centre, Institute of Psychiatry, King's College London, London, UK
}

\author{
Edited by: \\ Antonio Cerasa, Institute of \\ Bioimaging and Molecular \\ Physiology-CNR, Italy \\ Reviewed by: \\ Fabrizio Piras, IRCCS Santa Lucia \\ Foundation, Italy \\ Giulia Donzuso, University of Catania, \\ Italy

\section{*Correspondence:} \\ Anthony C. Vernon, Department of \\ Neuroscience, James Black Centre, \\ Institute of Psychiatry, King's College \\ London, 125 Coldharbour Lane, \\ London SE5 9NU, UK \\ e-mail: anthony.vernon@kcl.ac.uk
}

\begin{abstract}
Dopamine replacement therapy in the form of levodopa results in a significant proportion of patients with Parkinson's disease developing debilitating dyskinesia. This significantly complicates further treatment and negatively impacts patient quality of life. A greater understanding of the neurobiological mechanisms underlying levodopa-induced dyskinesia (LID) is therefore crucial to develop new treatments to prevent or mitigate LID. Such investigations in humans are largely confined to assessment of neurochemical and cerebrovascular blood flow changes using positron emission tomography and functional magnetic resonance imaging. However, recent evidence suggests that LID is associated with specific morphological changes in the frontal cortex and midbrain, detectable by structural MRI and voxel-based morphometry. Current human neuroimaging methods however lack sufficient resolution to reveal the biological mechanism driving these morphological changes at the cellular level. In contrast, there is a wealth of literature from well-established rodent models of LID documenting detailed post-mortem cellular and molecular measurements. The combination therefore of advanced neuroimaging methods and rodent LID models offers an exciting opportunity to bridge these currently disparate areas of research. To highlight this opportunity, in this mini-review, we provide an overview of the current clinical evidence for morphological changes in the brain associated with LID and identify potential cellular mechanisms as suggested from human and animal studies. We then suggest a framework for combining small animal MRI imaging with rodent models of LID, which may provide important mechanistic insights into the neurobiology of LID.
\end{abstract}

Keywords: levodopa, magnetic resonance imaging, $T_{1}$ relaxation, voxel-based morphometry, plasticity, prefrontal cortex

\section{INTRODUCTION}

Parkinson's disease (PD) is a multi-system neurodegenerative disorder that affects 1 in 100 people aged over 60 in the United Kingdom. The disease is characterized pathologically by the progressive degeneration of nigrostriatal dopamine (DA) containing neurons in the substantia nigra (1) and the accumulation of phosphorylated $\alpha$-synuclein in Lewy bodies, ascending from the brain stem to the higher area association cortices as the disease progresses (2). The subsequent depletion of DA in the caudate and putamen of PD patients manifests itself as the classical triad of PD motor symptoms, akinesia, resting tremor, and rigidity/postural instability.

Some 44 years since its first use in the clinic (3), the firstline treatment for many PD patients to alleviate their motor symptoms remains pharmacological DA replacement with the DA precursor levodopa (L-DOPA) (4). Although most patients respond positively to L-DOPA treatment, after $\sim 4-6$ years of LDOPA therapy, a significant proportion of patients $(\sim 40 \%)$ exhibit a decline in the therapeutic efficacy of L-DOPA and develop debilitating dyskinesias (5). This phenomenon, termed levodopainduced dyskinesia (LID), is characterized by involuntary dystonic and/or choreic movements of the trunk, limbs, and face, most commonly when the plasma concentration of DA is high ("peak dose" dyskinesia) (5). The expression of LID severely limits the long-term clinical utility of L-DOPA in this sub-set of PD patients and thus significantly impacts on patient quality of life. As such, strategies to mitigate or prevent LID onset are the subject of intense research efforts to address this serious unmet medical need. In the clinic, these efforts are currently centered on modifying the timing, formulation, and mode of administration for L-DOPA. In particular, emphasis is placed on delaying L-DOPA treatment where possible by use of direct-acting DA receptor agonists (6) and if not possible, using continuous intestinal L-DOPA infusion rather than intermittent L-DOPA injections (7). Both approaches have met with some success in reducing the incidence and severity of LID. At the pre-clinical level, significant effort is being directed toward understanding the role of other neurotransmitter systems in LID, particularly the role of glutamate and serotonin, as well 
as the underlying molecular signaling pathways involved (8-10). Despite these efforts, the neural mechanisms underlying LID in PD remain obscure and the underlying neural correlates are not well understood. This presents a significant barrier to development of novel treatments (11).

In this article, we therefore examine current clinical evidence that suggests neuroanatomical changes in the brain are associated with LID, and the caveats associated with this. Second, we identify potential post-mortem cellular mechanisms as suggested from human and animal studies, which may explain these abnormalities. Thirdly, we outline the framework for combining small animal imaging with rodent models of LID, which may provide important mechanistic insights into the neurobiology of LID.

\section{NEURAL CORRELATES OF LEVODOPA-INDUCED DYSKINESIA:} functional MRI STUDIES

Research efforts to unravel the neural correlates of LID in the clinic and in relevant animal models of LID are critical to address the gaps in our knowledge of LID pathogenesis (12,13). A fruitful and translational strategy that can bridge clinical and pre-clinical studies to achieve this is the application of neuroimaging tools to both human patients and relevant animal models. In particular, the latter can provide a mechanistic framework to underpin neuroimaging observations in patients.

To date, such investigations have typically focused on the use of functional magnetic resonance imaging (fMRI) and positron emission tomography (PET). These studies have identified changes in brain network activity, metabolism and molecular changes related to LID onset and severity, as described elsewhere (14-17). In brief, it is clear from these studies that LID is associated with bi-directionally altered neuronal firing patterns between the basal ganglia and the neocortex, the net result of which is dis-inhibition of thalamo-cortical neurons, leading to over-activation of frontal cortical areas, particularly in the motor, pre-motor, and prefrontal cortices. These data have been confirmed in PD patients with LID using PET $(14,18)$, transcranial magnetic stimulation [TMS; Ref. (19)], task-based and resting state fMRI $(17,20,21)$.

\section{NEUROANATOMICAL CORRELATES OF LEVODOPA-INDUCED DYSKINESIA: STRUCTURAL MRI STUDIES}

Functional magnetic resonance imaging studies have revealed several important insights into LID pathophysiology. However, it is also true that human neuroimaging studies consistently demonstrate a linear relationship between the functional activity of the brain, assessed by fMRI and the shape, volume, or thickness of brain gray matter (22-24). These findings hold true for rodents as well $(25,26)$. This structure-function relationship is most likely driven by neuroanatomical remodeling at the cellular, synaptic (neuronal dendrite), or vascular level as a consequence of altered brain functional or metabolic activity $(23,27,28)$. In other words, changes in brain function usually lead to or are concurrent with changes in the structure of the brain. Taking this into consideration, it is perhaps surprising that the use of structural MRI (sMRI) to probe whether there are neuroanatomical differences between patients with LID and those who are not dyskinetic has not been widely investigated.
In a recent study, the first of its kind to address this issue, Cerasa et al. (29) utilized optimized voxel-based morphometry (VBM) to analyze $\mathrm{T}_{1}$-weighted $\mathrm{MR}$ images from $\mathrm{PD}$ patients with LID $(n=36)$, non-dyskinetic PD patients $(n=36)$, and ageand sex-matched controls $(n=32)$. Compared to healthy controls, both dyskinetic and non-dyskinetic PD patients showed no significant differences in gray matter volume (GMV), somewhat consistent with other VBM findings in PD patients of a similar age and disease duration, although the sample size was small (29). However, when comparing dyskinetic versus nondyskinetic PD patients directly, a significant increase in GMV was observed in the bilateral inferior frontal gyrus of the dyskinetic patients (29). This increase was negatively correlated to age at onset, such that the greatest increases in inferior frontal gyrus GMV were in LID expressing PD patients with younger age of onset (29). These data suggest a hypothesis that aberrant striatofrontal and/or thalamo-cortical neural plasticity associated with LID consequently leads to morphological remodeling of the prefrontal cortex (29), findings which have sparked an interesting debate $(30,31)$.

The normalization and smoothing processes inherent to the VBM pipeline may however lead to reduced sensitivity in assessing cortical pathology, since individual sulci and gyri cannot be accurately anatomically resolved $(32,33)$. As such, VBM therefore provides a mixed measure of gray matter reflecting two components, cortical surface area and cortical thickness. A direct measure of cortical thickness therefore represents a topographical measurement that might provide a more sensitive indicator of the integrity of the cytoarchitecture in the cortex $(32,33)$.

To address this, Cerasa et al. (34) used surface-based investigation of cortical thickness in PD patients with LID $(n=29)$, without LID $(n=30)$, and age- and sex-matched controls $(n=24)$. This analysis revealed a pronounced increase in the thickness of the right inferior frontal sulcus in the dyskinetic, as compared to nondyskinetic patients (34). These data support their original VBM findings (29) and delineate with greater precision the anatomical abnormalities characterizing dyskinetic PD patients (34). A third study combining VBM and cortical thickness measurements in PD patients with LID $(n=33)$ or without LID $(n=33)$, stratified by their PD age-of-onset ( $<$ or $>50$ years of age), compared to age- and sex-matched healthy controls $(n=40)$ reveals further insights (35). Independent of the age of PD onset, dyskinetic patients were characterized by increased GMV and thickness in the inferior frontal cortex (35). Interestingly, early-onset PD patients with dyskinesia also demonstrated increased GMV in the substantia nigra and the red nucleus when compared to non-dyskinetic patients (35). In contrast, late-onset PD patients with dyskinesia were characterized by GMV increases in the supplementary motor area (SMA) only (35). Taken together, these data support the previous observations of anatomical abnormalities associated more generally with LID in the prefrontal cortex. Moreover, they demonstrate that different spatial patterns of brain abnormalities occur in patients with LID according to their age of PD onset. In particular, nigral pathology may be important in earlyonset patients and in contrast, cortical pathology in late-onset patients (35). 


\section{LEVODOPA, GRAY MATTER, AND MAGNETIC RESONANCE IMAGING SIGNAL}

When interpreting VBM results, it is important to eliminate artificial causes for differences between processed images that do not originate from genuine biological differences. In particular, MR image contrast between tissue classes on $\mathrm{T}_{1}$-weighted MR images is inversely proportional to the $\mathrm{T}_{1}$ relaxation time. Cerebrospinal fluid (CSF) is dark, reflecting a long $\mathrm{T}_{1}$; whereas the much shorter $\mathrm{T}_{1}$ of white matter renders it bright; and gray matter is intermediate between these. When the brain is segmented into these different tissue classes for volumetric analysis, VBM (and other automated techniques, including cortical thickness) utilizes voxel signal intensity profile (36). Each voxel has its own distinct intensity profile and there is substantial overlap in the voxel intensity histograms linked to gray and white matter. This renders precise tissue class segmentation difficult, particularly in the presence of partial volume effects, wherein a single voxel contains a mixture of tissue types (37). This is particularly common when a voxel spans distinct tissues, in cortical sulci (38). Such voxels are usually excluded or allocated to a particular tissue type on a probabilistic basis. As such, this segmentation process has the potential to go awry in the presence of unrecognized changes in voxel intensity profiles, leading to spurious volumetric findings (37). In other words, a reported volume change might in fact be an artifact of the signal acquisition and image analysis process (37).

This has recently been advanced as a biophysical explanation for the effects of lithium, a mood stabilizer, to apparently increase GMV (37). Whilst this notion is debated (39-41) and has yet to be explored in detail, it is certainly important and warrants attention $(40,41)$.

Interestingly, L-DOPA is associated with shortening of $\mathrm{T}_{1}$ (and $\mathrm{T}_{2}$ ) relaxation time in vitro, although this may be influenced by the presence of iron (42). This raises the possibility that changes in $\mathrm{T}_{1}$ in the human brain after L-DOPA administration may lead to an adjustment in the number of voxels that are attributed to gray matter. These would then be detected by VBM analysis as an apparent increase in GMV. Consistent with this hypothesis, VBM analysis reports an increase in voxels attributed to gray matter in the substantia nigra, ventral tegmental area, and subthalamic nucleus following acute L-DOPA administration in healthy volunteers (43). Unfortunately, this study did not include quantitative $\mathrm{T}_{1}$ parametric mapping to assess the impact of $\mathrm{L}_{\mathrm{D}} \mathrm{DOPA}$ on $\mathrm{T}_{1}$ in vivo.

These findings following a single administration of L-DOPA to healthy people may lead to the suggestion differences in anatomical MRI data acquired from dyskinetic and non-dyskinetic PD patients $(29,34,35)$, are driven by simple changes in signal intensity (grounded in increases in proton $\mathrm{T}_{1}$ ), which may be misinterpreted as a volume increase in the gray matter. Importantly, therefore, the gray matter volume increases reported in dyskinetic PD patients were detected only in dyskinetic patients compared to non-dyskinetic patients. All of these patients were receiving L-DOPA therapy at the time of scanning, with no significant difference in the duration of L-DOPA treatment $(29,34,35)$.

Taken together, this does not support a general influence of L-DOPA on the MRI signal driving the observed results, since such an effect would be predicted to be present in both L-DOPA treated patient groups. The fact that the anatomical abnormalities are only present in the dyskinetic group strongly suggests these are inherently linked to the pathogenesis of LID. We note however that Lewis and colleagues report an accumulation of iron in the red nucleus of patients with L-DOPA-induced dyskinesia (44). Iron is paramagnetic and causes a reduction in both $\mathrm{T}_{2}$ and $\mathrm{T}_{1}$ relaxation time in brain regions where brain iron is deposited in the form of ferritin and hemosiderin (45). As such, whilst there is no evidence currently to suggest that neuroanatomical brain changes in dyskinetic PD patients are the result of an MR image artifact, quantitative $T_{1}$ and $T_{2}$ mapping may be recommended for future MRI studies in dyskinetic and non-dyskinetic patients. This would help to more accurately probe the exact origins of MRI signal changes in these groups. Alternatively, controlled animal studies may be important as MRI volume changes can be verified post-mortem, as we have shown previously $(28,39,46,47)$, and discussed later in this article.

\section{WHAT IS THE MECHANISM UNDERLYING NEUROANATOMICAL CHANGE IN GRAY MATTER FOLLOWING CHRONIC L-DOPA TREATMENT?}

Assuming that dyskinesia following L-DOPA treatment is associated with physical neuroanatomical changes in the brain, the next obvious issue is the identification of the underlying biological mechanism. However, neuroimaging measures are difficult to relate unambiguously to underlying biology (23). In particular, human neuroimaging studies cannot establish if the morphological abnormalities in the prefrontal cortex of dyskinetic $\mathrm{PD}$ patients are a cause or consequence of dyskinesia, following chronic L-DOPA treatment (29). One very plausible hypothesis is that these morphological changes reflect heightened activity within the neuronal circuitry implicated in LID pathogenesis (29). In other words, the detected pattern of brain abnormalities reflects altered neurobiological mechanisms central to the pathogenesis of LID. This hypothesis is supported by observations in hyperkinetic movement disorders such as dystonia. Indeed, dystonia is associated with exaggerated increases in GMV of specific brain regions involved in somatosensory processing, such as the basal ganglia, prefrontal cortex, and somatosensory cortex $(35,48)$. Furthermore, it is suggested that L-DOPA, when applied in a pulsatile and non-physiological manner may perturb the normal physiological mechanisms that mediate motor control (49). This process may lead to aberrant increases in synaptic plasticity, remodeling of neuronal synapses, and changes in the functional connectivity signature of brain activity within circuits responsible for motor control. At the cellular level, this is likely to manifest as increases in the size of neuronal dendritic arbors $(50,51)$. This phenomenon termed, "L-DOPA-maladaptive plasticity" may be critical to LID pathogenesis (29). Interestingly, this has also been suggested as an explanation for the incidence of tardive dyskinesia following chronic treatment with first generation antipsychotic drugs (52).

Evidence from recent studies using electroencephalography (EEG) and fMRI support this hypothesis. These reveal that brain activity and functional connectivity, defined as spontaneous, temporally coupled blood oxygen level dependent (BOLD) oscillations, is decreased in $\mathrm{PD}$ patients within the motor circuit in the cortex that receives dopaminergic innervation including the frontal, somatosensory, motor, and SMA (20, 21, 53-55). 
Furthermore, these studies confirm that acute and chronic L-DOPA treatment restores this lost connectivity with motor networks and increases neural activity in these brain regions (20, 21, 53-55). In an acute setting, this may explain the therapeutic effects of L-DOPA. However, with chronic treatment and the continued degeneration of the dopaminergic system, this could result in L-DOPA maladaptive plasticity leading to changes in neural arborization, and subsequently the observed neuroanatomical increases in the cortex of dyskinetic PD patients. Alternatively, such neuroanatomical enlargements could equally reflect a structural long-term consequence of the altered neural plasticity in these specific regions.

In reality however, MR phenomena are likely to be driven by several cellular processes; acting potentially in parallel in multiple cell types within the brain (23). Neuronal changes in gray matter as a cause or consequence of chronic L-DOPA treatment may include neurogenesis, synaptogenesis, and changes in neuronal morphology as discussed above. However, extra-neuronal changes may equally be responsible and these could include increases in glial cell size, morphology, number and additionally, angiogenesis. Indeed, the vasculature accounts for about $5 \%$ of gray matter (56). Glial cells (astrocytes, microglia, and oligodendrocytes) are believed to outnumber neurons by $\sim 6$ to 1 , with varying ratios in different brain regions. Any of these cellular changes may influence MRI signals. Importantly, variations in neuronal, glial, and synaptic density may affect modalities sensitive to the proportion of cellular material versus extracellular space in a voxel, such as proton density imaging or relaxometry. Such features would therefore influence commonly used methods to assess gray matter change including VBM and cortical thickness that rely on image intensity boundaries in $\mathrm{T}_{1}$-weighted images (54).

Addressing this issue is problematic. In patients, one fruitful approach may be to conduct multi-modal neuroimaging in dyskinetic and non-dyskinetic PD patients to study the interrelationships between brain function, metabolism, and structure. This could include, but is not limited to, collection of resting state fMRI, sMRI and quantitative $\mathrm{T}_{1}$ mapping in the same session. Similarly, angiogenesis could be detected by techniques such as contrastenhanced imaging of blood volume or perfusion imaging of cerebral blood flow (CBF). Recent advances in simultaneous PETMRI, the feasibility of which has been demonstrated in rodents $(57)$ and humans $(58,59)$ make this even more tractable and could provide unparalleled insights into the pathophysiology of LID.

Ultimately, post-mortem histological studies are required in order to make direct links between imaging measures and underlying mechanisms. For example, recent studies in our laboratory have established that neuroanatomical changes, including a reduction in the volume of the anterior cingulate cortex due to chronic antipsychotic drug treatment are not due to the loss of neurons or astrocytes (28). Similarly, in a very elegant study, mice subjected to different forms of maze training displayed volume increases in either the hippocampus (spatial maze) or striatum (cued maze), reflecting the distinct brain systems involved in these tasks (27). These MRI-derived measures of growth correlated with growth associated protein-43 (GAP-43) staining post-mortem, a marker for axonal growth cones, but not measures of neuronal size or number (27). These data suggest the observed MRI volume change reflected remodeling of neuronal processes, rather than neurogenesis (27). These data highlight the need to study relevant animal models to help unravel the neuroanatomical correlates of LID observed on MRI in patients.

\section{ANIMAL MODELS OF LID}

Levodopa-induced dyskinesia can be modeled pre-clinically by recapitulating the conditions required for its development in humans, namely degeneration of the nigrostriatal tract followed by chronic exposure to L-DOPA. The primary dopaminergic cell loss models used for evaluation of dyskinesia are the 6-hydroxydopamine (6-OHDA) lesioned hemi-parkinsonian rat and the 1-methyl-4-phenyl-1,2,3,6-tetrahydropyridine (MPTP)treated non-human primate (NHP). Repeated exposure of these denervated animals over several weeks to daily treatment with L-DOPA combined with a peripheral DOPA decarboxylase inhibitor such as benserazide or carbidopa, leads to development of abnormal involuntary movements (AIMs), which is considered an experimental proxy for human LID (13, 60-62). This can be scored according to a variety of ratings scales $(63,64)$. In the 6-OHDA-lesioned rat, AIMs manifest unilaterally as axial (twisting of the head, neck, and trunk), limb (repetitive or dystonic movements involving the forepaw and/or limb), and orolingual (vacuous chewing, tongue protrusion) phenomena on the side of the body contralateral to the lesion (60). In MPTP-treated NHPs, LID is bilaterally expressed and manifests as choreic and dystonic movements of the limbs, especially the lower limbs, and flicking of the fingers, trunk dystonias, and repetitive tongue protrusion (65). The MPTP-NHP model more accurately reflects the human expression of dyskinesia, but ethical and practical considerations mean that the 6-OHDA-lesioned rat model is a very valuable tool for pre-clinical research. Importantly, the mechanisms underlying the development of LID and AIMs appear to be common to both (13). Extensive research in both rat and NHP LID models, including studies to assess the potential of new anti-dyskinetic drug strategies, has identified a plethora of candidate mechanisms in specific brain regions, which may underlie the pathogenesis of LID $(5,66)$. Both striatal and extra-striatal systems are implicated, as described in brief below.

\section{STRIATAL MECHANISMS UNDERLYING LID}

The role of DA in the striatum is to alter the response of medium spiny neurons (MSNs) in both the direct and indirect pathways to excitatory input from the corticostriatal pathway. The classical model of LID suggests the presence of high concentrations of exogenous DA (derived from L-DOPA) causes hyperactivation of the direct pathway (striatonigral) MSNs, which increases thalamocortical feedback and produces exaggerated motor function. Dyskinesia is therefore believed to primarily involve chronic overactivation of striatonigral MSNs $(67,68)$ and there is a wealth of evidence for a particular role of dopamine D1 receptors (D1R) in the development of LID in both patients and pre-clinical models (69-72). In reality the mechanisms involved are likely to be considerably more complex (73) and a role for the indirect pathway cannot be ruled out, especially as both D1R and dopamine D2 receptor (D2R) agonists can provoke dyskinesia in primed monkeys (74). 
The striatonigral GABAergic projection is a point of convergence for, and is therefore modulated by, multiple neurotransmitter systems that may be pathologically altered in dyskinetic PD patients. The major input to the BG involves release of glutamate from corticostriatal neurones, and together with DA and the modulatory activity of other neurotransmitters such as serotonin (5HT), this determines the activity of the output nuclei: the globus pallidus internus (GPi) and substantia nigra pars reticulata $(\mathrm{SNr})$. There is evidence from animal models that this corticostriatal glutamate release is increased in $\operatorname{LID}(75,76)$, alongside alterations in expression (69,77-80), phosphorylation (81-83), and distribution $(84,85)$ of glutamate receptors, including NR1/NR2B NMDA receptors and metabotropic glutamate receptor $5\left(\mathrm{mGlu}_{5}\right)$, that facilitate increased signaling across this synapse. Morphological alterations indicative of increased glutamatergic transmission are also present (86). This is borne out in human LID, where abnormal glutamatergic transmission has been described in the caudate, putamen, and motor cortex (87), alongside increased putaminal expression of NR1/NR2B NMDA receptors (88) and $\mathrm{mGlu}_{5}$ receptors (80). Activation of extrasynaptic NR2B-containing NMDA receptors has particularly been implicated in the development of LID (84).

The effect of this abnormal glutamatergic transmission may be compounded by the consequences of dysregulated release of DA from serotonergic terminals within the striatum (89), leading to abnormal activation of DA receptors. These receptors are expressed on striatonigral MSNs as well as in cortical dopaminergic systems, which have also been implicated in the pathophysiology of dyskinesia (90). There are some reports of altered D1R expression or trafficking in $\operatorname{LID}(70,91)$, but evidence suggests that the key mechanism in dyskinesia is increased functional sensitivity of these receptors $(92,93)$.

Whatever the exact mechanism behind increased D1R signaling, stimulation of these receptors causes activation of the cyclic AMP (cAMP)/protein kinase A (PKA)/DARPP-32 (DA- and cAMP-regulated phosphoprotein, $32 \mathrm{kDa}$ )/protein phosphatase 1 (PP-1) pathway and the mitogen activated protein kinase (MAPK) pathway, which culminates in phosphorylation of extracellular signal related kinase (ERK1/2) (94). This results in DNA modifications $(95,96)$ and increased expression of transcription factors, especially $\Delta$ FosB/FosB (97), which are indicative of long-term cellular adaptations.

Both NMDA and $\mathrm{mGlu}_{5}$ receptors are known to closely interact with $\operatorname{D1R}(81,98)$ and with each other $(99,100)$, activating common downstream mediators such as PKA and ERK1/2 $(101,102)$. Therefore, the increased expression of these receptors alongside enhanced D1R signaling will co-operate to augment striatonigral signaling in LID. In addition, activation of D1R, in combination with enhanced activation of NMDA receptors by glutamate, leads to long-term potentiation-like phenomena. This may explain the lack of depotentiation seen in the dyskinetic versus non-dyskinetic denervated striatum (103), leading to an exaggerated response to normally irrelevant stimuli. The pathological overactivation of the direct pathway leads to GABA bursting in the SNr and GPi (71), thus disinhibiting thalamocortical feedback and leading to the hyperkinetic movements characteristic of LID.
Striatal glutamatergic and dopaminergic transmission can be modulated by several other neurotransmitters. For example, increased serotonergic innervation of the striatum, along with altered expression of several receptor subtypes $(104,105)$, has been demonstrated in animal and human $\operatorname{LID}(106,107)$. Importantly, activation of serotonin $5-\mathrm{HT}_{1 \mathrm{~A}}$ receptors has been shown to reduce corticostriatal glutamate release $(108,109)$, and also negatively regulates release of DA as a false neurotransmitter from serotonergic terminals (110). Similarly the endocannabinoid system may play a role in LID as activation of $\mathrm{CB}_{1}$ receptors has been shown to negatively regulate corticostriatal glutamate release $(111,112)$ and also reduce D1R-mediated responses (113-115). Consequently, molecules such as serotonin receptor $5-\mathrm{HT}_{1 \mathrm{~A}}$ and $5-\mathrm{HT}_{1 \mathrm{~B}}$ agonists (116-120) and endocannabinoid receptor agonists (121-124) have shown anti-dyskinetic efficacy.

\section{EXTRA-STRIATAL MECHANISMS OF LID}

As well as striatal alterations, there is also evidence from pharmacological studies suggesting that modulation of neurotransmission elsewhere in the BG and in areas of the cortex may also contribute to LID. Systemically active drugs could therefore produce antidyskinetic effects through actions at more than one key synapse. For example, antagonists of $\mathrm{mGlu}_{5}$, which are currently in clinical trials as anti-dyskinetic agents $(125,126)$, may exert their effects not only in the striatum but also in the subthalamic nucleus (127). Targeting of $5-\mathrm{HT}_{1 \mathrm{~A}}$ receptors in the subthalamic nucleus (128) or primary motor cortex (129) also attenuates dyskinesia, as does activation of $5-\mathrm{HT}_{1 \mathrm{~B}}$ receptors $(130,131)$, which are not only present in the striatum but also on GABAergic MSNs terminating in the $\mathrm{SNr}$, where their activation can inhibit GABA release (132). As well as the striatal actions already mentioned, another potential mechanism to explain the efficacy of $\mathrm{CB}_{1}$ agonists is potentiation of striatopallidal signaling via inhibition of GABA reuptake (121), which would help to rebalance a hyperactivation of striatonigral signaling. Opioid signaling, which is known to be altered in LID (133-135), can modulate transmitter release at several synapses within the BG, for example inhibition of striatopallidal GABA release (136), and inhibition of glutamate and GABA release into the $\mathrm{SNr}$ (137). Targeting several opioid receptor subtypes has shown anti-dyskinetic efficacy (138-141), but their role is complex and the effects of opioid-targeted approaches may be dose-dependent (137).

\section{FUTURE DIRECTIONS: A TRANSLATIONAL ROAD MAP TO BRIDGE ANIMAL MECHANISTIC STUDIES WITH BRAIN STRUCTURAL IMAGING TO IDENTIFY THE MORPHOLOGICAL CORRELATES OF LID}

These maladaptive plastic changes described above in the striatum and extra-striatal regions may well underlie the morphological changes associated with LID described in humans. Combining well-validated rat and potentially, NHP, models of LID with advanced non-invasive animal MR imaging methods therefore offers an exciting opportunity to integrate currently disparate areas of research and help explain the MR imaging phenomena observed in dyskinetic patients (31) (Figure 1). This approach is advantageous for three reasons. First, rodents and primates allow one to assess the precise effects of drug treatment (in this 


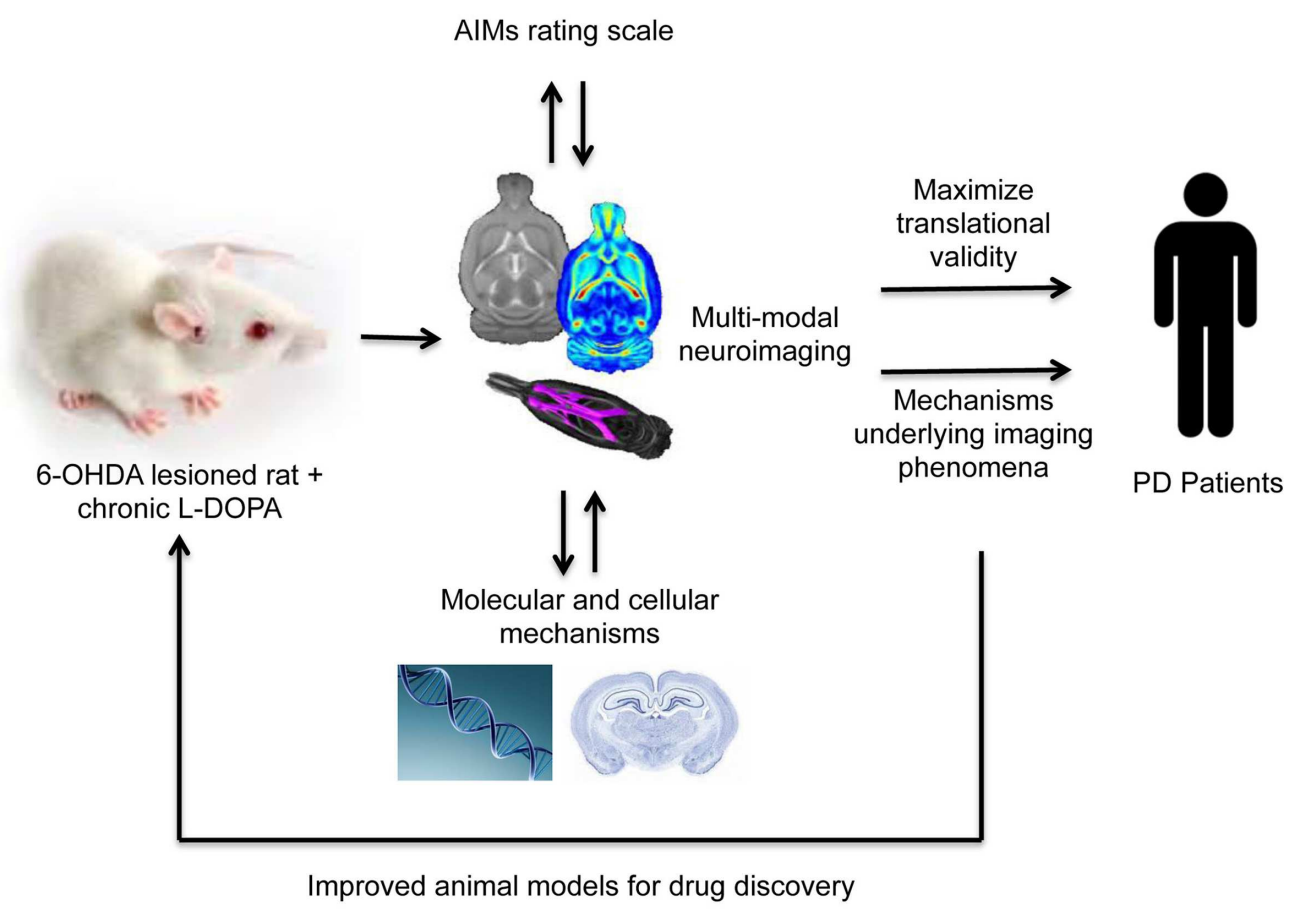

FIGURE 1 |A translational methodological framework for the combination of rodent models of LID (or these could be non-human primates) with multi-modal imaging, behavior and post-mortem cellular, or molecular analysis to elucidate the mechanisms underlying imaging phenomena associated with levodopa dyskinesia observed in human Parkinson's disease patients.

case, L-DOPA) on brain structure and function, disentangled from potential confounding factors present in patient samples. The proof-of-concept for this approach has been recently demonstrated in our laboratory in characterizing the impact of chronic antipsychotic drug treatment on rat brain morphometry $(28,39$, 142). Second, the use of MRI/PET (clinically comparable technology) permits the collection of parallel data read-outs in rodents, primates, and humans, maximizing the possibility for translation of basic findings to the clinic. Thirdly, and most importantly, as we have seen in the preceding section, in animals one can measure neurochemical, biochemical, cellular, and molecular aspects of brain structure and function in ways that are impossible in human subjects. Thus neuroimaging and neuropathology may be bridged to identify the biological mechanisms underlying MRI phenomena.

A number of elegant functional imaging studies using small animal micro-PET technology have begun to address this. Studies using PET in 6-OHDA lesioned rats chronically treated with L-DOPA and displaying severe AIMs (the rodent LID phenotype) display regional increases in CBF (measured using [14C]-iodoantipyrine uptake), increases in regional cerebral glucose utilization (rCGU; measured using [14C]-2-deoxyglucose uptake) and DA release (measured using displacement of [11C]raclopride binding potential), consistent with similar findings in PD patients (143-145). To date however, no studies have assessed the impact of L-DOPA treatment on brain morphometry or relaxation time in either rodent or primates, using advanced structural MR imaging methods. This approach offers a unique opportunity to answer a number of outstanding questions in the emerging field of neuroanatomical alterations linked to LDOPA and LID pathogenesis. Multi-modal imaging approaches, to study the interrelationships between brain anatomy [sMRI, Diffusion Tensor Imaging (DTI)] metabolism [2-dexoyglucose, ${ }^{1} \mathrm{H}$-magnetic resonance spectroscopy (MRS)] and fMRI may be of particular relevance. These imaging findings may then serve as a "roadmap" to guide follow-up, region-specific post-mortem investigation of the candidate mechanisms already identified in these models, to help explain the imaging phenomena. Excitingly, such studies are now underway in our laboratory.

Combining experimental models of LID with clinically comparable technology may also be particularly important for the assessment of novel anti-dyskinetic drugs, such as antagonists of mGlu . Indeed, as previously stated, the use of clinically comparable technology (MRI) to conduct parallel assessments in experimental animals and humans is likely to accelerate translation of basic findings to the clinic. Neuroimaging tools may therefore play a critical role in future studies evaluating not only target engagement, but also drug efficacy in models of LID, as evidenced by recent studies using PET $(143,144,146)$. No studies as yet have employed MRI methods, but the potential for application of this technology is apparent.

\section{CONCLUSION}

Recent human sMRI studies in PD patients with dyskinesia have suggested the presence of neuroanatomical changes in specific brain regions, particularly the frontal cortex, which may have 
relevance to the pathogenesis of dyskinesia. It is currently unclear from these studies whether these abnormalities are the cause, or consequence of dyskinesia. Furthermore, it is unclear if these reflect genuine neuroanatomical changes in shape, thickness, or volume of gray matter, or whether these can be explained by a biophysical hypothesis relating to L-DOPA, as recently described for the effects of lithium. Accepting this caveat and presuming these changes to be genuine structural differences in gray matter, the biological mechanism underlying these changes remain unknown, but may be rooted in maladaptive neuronal plasticity, leading to remodeling of synapses and dendrites on neurons and glia alike in the dyskinetic brain. However, a plethora of data for candidate mechanisms underlying the pathophysiology of LID exists from well-validated rodent and NHP pre-clinical models of LID, which display excellent construct, face, and predictive validity to human LID. The combination of these models with advanced, multi-modal small animal MR imaging technology therefore offers a unique opportunity to validate the presence of neuroanatomical changes associated with LID. Furthermore, this will be an important step to bridge neuroimaging and neuropathology to link candidate mechanisms derived from animal models with neuroimaging phenomena in dyskinetic PD patients. Ultimately, this will accelerate our understanding of LID pathogenesis and aid the discovery and evaluation of novel anti-dyskinetic drug treatments.

\section{REFERENCES}

1. Fearnley JM, Lees AJ. Ageing and Parkinson's disease: substantia nigra regional selectivity. Brain (1991) 114(Pt 5):2283-301. doi:10.1093/brain/114.5.2283

2. Braak H, Del Tredici K, Rub U, De Vos RA, Jansen Steur EN, Braak E. Staging of brain pathology related to sporadic Parkinson's disease. Neurobiol Aging (2003) 24:197-211. doi:10.1016/S0197-4580(02)00065-9

3. Yahr MD, Duvoisin RC, Schear MJ, Barrett RE, Hoehn MM. Treatment of parkinsonism with levodopa. Arch Neurol (1969) 21:343-54. doi:10.1001/ archneur.1969.00480160015001

4. Schapira AH, Emre M, Jenner P, Poewe W. Levodopa in the treatment of Parkinson's disease. Eur J Neurol (2009) 16:982-9. doi:10.1111/j.1468-1331. 2009.02697.x

5. Iravani MM, Jenner P. Mechanisms underlying the onset and expression of levodopa-induced dyskinesia and their pharmacological manipulation. $J$ Neural Transm (2011) 118:1661-90. doi:10.1007/s00702-011-0698-2

6. Olanow CW, Stocchi F. Why delaying levodopa is a good treatment strategy in early Parkinson's disease. Eur J Neurol (2000) 7(Suppl 1):3-8. doi:10.1046/j. 1468-1331.2000.00032.x

7. Olanow CW, Obeso JA, Stocchi F. Continuous dopamine-receptor treatment of Parkinson's disease: scientific rationale and clinical implications. Lancet Neurol (2006) 5:677-87. doi:10.1016/S1474-4422(06)70521-X

8. Fasano S, Bezard E, D’Antoni A, Francardo V, Indrigo M, Qin L, et al. Inhibition of Ras-guanine nucleotide-releasing factor 1 (Ras-GRF1) signaling in the striatum reverts motor symptoms associated with L-dopa-induced dyskinesia. Proc Natl Acad Sci U S A (2010) 107:21824-9. doi:10.1073/pnas.1012071107

9. Duty S. Targeting glutamate receptors to tackle the pathogenesis, clinical symptoms and levodopa-induced dyskinesia associated with Parkinson's disease. CNS Drugs (2012) 26:1017-32. doi:10.1007/s40263-012-0016-z

10. Navailles S, Lagiere M, Contini A, De Deurwaerdere P. Multisite intracerebral microdialysis to study the mechanism of L-DOPA induced dopamine and serotonin release in the parkinsonian brain. ACS Chem Neurosci (2013) 4:680-92. doi:10.1021/cn400046e

11. Jenner P. Preventing and controlling dyskinesia in Parkinson's disease - a view of current knowledge and future opportunities. Mov Disord (2008) 23(Suppl 3):S585-98. doi:10.1002/mds.22022

12. Brotchie JM, Lee J, Venderova K. Levodopa-induced dyskinesia in Parkinson's disease. J Neural Transm (2005) 112:359-91. doi:10.1007/s00702-004-0251-7
13. Duty S, Jenner P. Animal models of Parkinson's disease: a source of novel treatments and clues to the cause of the disease. Br J Pharmacol (2011) 164:1357-91. doi:10.1111/j.1476-5381.2011.01426.x

14. Brooks DJ, Piccini P, Turjanski N, Samuel M. Neuroimaging of dyskinesia. Ann Neurol (2000) 47:S154-8; discussion S158-159.

15. Rascol O, Brooks DJ, Korczyn AD, De Deyn PP, Clarke CE, Lang AE. A five-year study of the incidence of dyskinesia in patients with early Parkinson's disease who were treated with ropinirole or levodopa. 056 Study Group. N Engl J Med (2000) 342:1484-91. doi:10.1056/NEJM200005183422004

16. Kuriakose R, Stoessl AJ. Imaging the nigrostriatal system to monitor disease progression and treatment-induced complications. Prog Brain Res (2010) 184:177-92. doi:10.1016/S0079-6123(10)84009-9

17. Cerasa A, Pugliese P, Messina D, Morelli M, Gioia MC, Salsone M, et al. Prefrontal alterations in Parkinson's disease with levodopa-induced dyskinesia during fMRI motor task. Mov Disord (2012) 27:364-71. doi:10.1002/mds. 24017

18. Rascol O, Sabatini U, Brefel C, Fabre N, Rai S, Senard JM, et al. Cortical motor overactivation in parkinsonian patients with L-dopa-induced peak-dose dyskinesia. Brain (1998) 121(Pt 3):527-33. doi:10.1093/brain/121.3.527

19. Koch G, Brusa L, Caltagirone C, Peppe A, Oliveri M, Stanzione P, et al. rTMS of supplementary motor area modulates therapy-induced dyskinesias in Parkinson disease. Neurology (2005) 65:623-5. doi:10.1212/01.wnl. 0000172861.36430 .95

20. Cole DM, Beckmann CF, Oei NY, Both S, Van Gerven JM, Rombouts SA. Differential and distributed effects of dopamine neuromodulations on resting-state network connectivity. Neuroimage (2013) 78:59-67. doi:10.1016/j.neuroimage. 2013.04.034

21. Esposito F, Tessitore A, Giordano A, De Micco R, Paccone A, Conforti R, et al. Rhythm-specific modulation of the sensorimotor network in drugnaive patients with Parkinson's disease by levodopa. Brain (2013) 136:710-25. doi:10.1093/brain/awt007

22. Takeuchi H, Sekiguchi A, Taki Y, Yokoyama S, Yomogida Y, Komuro N, et al. Training of working memory impacts structural connectivity. JNeurosci (2010) 30:3297-303. doi:10.1523/JNEUROSCI.4611-09.2010

23. Zatorre RJ, Fields RD, Johansen-Berg H. Plasticity in gray and white: neuroimaging changes in brain structure during learning. Nat Neurosci (2012) 15:528-36. doi:10.1038/nn.3045

24. Fauvel B, Groussard M, Chetelat G, Fouquet M, Landeau B, Eustache F, et al. Morphological brain plasticity induced by musical expertise is accompanied by modulation of functional connectivity at rest. Neuroimage (2014) 90:179-88. doi:10.1016/j.neuroimage.2013.12.065

25. Biedermann S, Fuss J, Zheng L, Sartorius A, Falfan-Melgoza C, Demirakca T, et al. In vivo voxel based morphometry: detection of increased hippocampal volume and decreased glutamate levels in exercising mice. Neuroimage (2012) 61:1206-12. doi:10.1016/j.neuroimage.2012.04.010

26. Dodero L, Damiano M, Galbusera A, Bifone A, Tsaftsaris SA, Scattoni ML, et al. Neuroimaging evidence of major morpho-anatomical and functional abnormalities in the BTBR T+TF/J mouse model of autism. PLoS One (2013) 8:e76655. doi:10.1371/journal.pone.0076655

27. Lerch JP, Yiu AP, Martinez-Canabal A, Pekar T, Bohbot VD, Frankland PW, et al. Maze training in mice induces MRI-detectable brain shape changes specific to the type of learning. Neuroimage (2011) 54:2086-95. doi:10.1016/j. neuroimage.2010.09.086

28. Vernon AC, Crum WR, Lerch JP, Chege W, Natesan S, Modo M, et al. Reduced cortical volume and elevated astrocyte density in rats chronically treated with antipsychotic drugs-linking magnetic resonance imaging findings to cellular pathology. Biol Psychiatry (2014) 75:982-90. doi:10.1016/j.biopsych. 2013.09.012

29. Cerasa A, Messina D, Pugliese P, Morelli M, Lanza P, Salsone M, et al. Increased prefrontal volume in PD with levodopa-induced dyskinesias: a voxel-based morphometry study. Mov Disord (2011) 26:807-12. doi:10.1002/mds.23660

30. Aron AR, Obeso J. Is executive control used to compensate for involuntary movements in levodopa-induced dyskinesia? Mov Disord (2012) 27:339-40. doi: $10.1002 / \mathrm{mds} .24936$

31. Vernon AC, Modo M. Do levodopa treatments modify the morphology of the parkinsonian brain? Mov Disord (2012) 27:166-7. doi:10.1002/mds.24018

32. Lerch JP, Pruessner JC, Zijdenbos A, Hampel H, Teipel SJ, Evans AC. Focal decline of cortical thickness in Alzheimer's disease identified by 
computational neuroanatomy. Cereb Cortex (2005) 15:995-1001. doi:10.1093/ cercor/bhh200

33. Jubault T, Gagnon JF, Karama S, Ptito A, Lafontaine AL, Evans AC, et al. Patterns of cortical thickness and surface area in early Parkinson's disease. Neuroimage (2011) 55:462-7. doi:10.1016/j.neuroimage.2010.12.043

34. Cerasa A, Morelli M, Augimeri A, Salsone M, Novellino F, Gioia MC, et al. Prefrontal thickening in PD with levodopa-induced dyskinesias: new evidence from cortical thickness measurement. Parkinsonism Relat Disord (2013) 19:123-5. doi:10.1016/j.parkreldis.2012.06.003

35. Cerasa A, Salsone M, Morelli M, Pugliese P, Arabia G, Gioia CM, et al. Age at onset influences neurodegenerative processes underlying PD with levodopa-induced dyskinesias. Parkinsonism Relat Disord (2013) 19:883-8. doi:10.1016/j.parkreldis.2013.05.015

36. Ashburner J, Friston KJ. Voxel-based morphometry-the methods. Neuroimage (2000) 11:805-21. doi:10.1006/nimg.2000.0582

37. Cousins DA, Aribisala B, Nicol Ferrier I, Blamire AM. Lithium, gray matter, and magnetic resonance imaging signal. Biol Psychiatry (2013) 73:652-7. doi:10.1016/j.biopsych.2012.09.029

38. Rueda A, Acosta O, Couprie M, Bourgeat P, Fripp J, Dowson N, et al. Topologycorrected segmentation and local intensity estimates for improved partial volume classification of brain cortex in MRI. J Neurosci Methods (2010) 188:305-15. doi:10.1016/j.jneumeth.2010.02.020

39. Vernon AC, Natesan S, Crum WR, Cooper JD, Modo M, Williams SC, et al. Contrasting effects of haloperidol and lithium on rodent brain structure: a magnetic resonance imaging study with postmortem confirmation. Biol Psychiatry (2012) 71:855-63. doi:10.1016/j.biopsych.2011.12.004

40. Ferrier NI, Blamire AM, Cousins DA. Reply to: effects of lithium on magnetic resonance imaging signal might not preclude increases in brain volume after chronic lithium treatment. Biol Psychiatry (2013) 74:e41-2. doi:10.1016/ j.biopsych.2013.07.023

41. Vernon AC, Hajek T. Effects of lithium on magnetic resonance imaging signal might not preclude increases in brain volume after chronic lithium treatment. Biol Psychiatry (2013) 74:e39-40. doi:10.1016/j.biopsych.2012.12.028

42. Tosk JM, Holshouser BA, Aloia RC, Hinshaw DB Jr, Hasso AN, Macmurray JP, et al. Effects of the interaction between ferric iron and L-dopa melanin on $\mathrm{T} 1$ and $\mathrm{T} 2$ relaxation times determined by magnetic resonance imaging. Magn Reson Med (1992) 26:40-5. doi:10.1002/mrm.1910260105

43. Salgado-Pineda P, Delaveau P, Falcon C, Blin O. Brain T1 intensity changes after levodopa administration in healthy subjects: a voxel-based morphometry study. Br J Clin Pharmacol (2006) 62:546-51. doi:10.1111/j.1365-2125.2006. 02695.x

44. Lewis MM, Du G, Kidacki M, Patel N, Shaffer ML, Mailman RB, et al. Higher iron in the red nucleus marks Parkinson's dyskinesia. Neurobiol Aging (2013) 34:1497-503. doi:10.1016/j.neurobiolaging.2012.10.025

45. Vymazal J, Brooks RA, Baumgarner C, Tran V, Katz D, Bulte JW, et al. The relation between brain iron and NMR relaxation times: an in vitro study. Magn Reson Med (1996) 35:56-61. doi:10.1002/mrm.1910350108

46. Vernon AC, Johansson SM, Modo MM. Non-invasive evaluation of nigrostriatal neuropathology in a proteasome inhibitor rodent model of Parkinson's disease. BMC Neurosci (2010) 11:1. doi:10.1186/1471-2202-11-1

47. Vernon AC, Crum WR, Johansson SM, Modo M. Evolution of extra-nigral damage predicts behavioural deficits in a rat proteasome inhibitor model of Parkinson's disease. PLoS One (2011) 6:e17269. doi:10.1371/journal.pone.0017269

48. Egger K, Mueller J, Schocke M, Brenneis C, Rinnerthaler M, Seppi K, et al. Voxel based morphometry reveals specific gray matter changes in primary dystonia. Mov Disord (2007) 22:1538-42. doi:10.1002/mds.21619

49. Olanow CW, Obeso JA. Pulsatile stimulation of dopamine receptors and levodopa-induced motor complications in Parkinson's disease: implications for the early use of COMT inhibitors. Neurology (2000) 55:S72-7; discussion S78-81.

50. Linazasoro G. New ideas on the origin of L-dopa-induced dyskinesias: age, genes and neural plasticity. Trends Pharmacol Sci (2005) 26:391-7. doi:10.1016/ j.tips.2005.06.007

51. Morgante F, Espay AJ, Gunraj C, Lang AE, Chen R. Motor cortex plasticity in Parkinson's disease and levodopa-induced dyskinesias. Brain (2006) 129:1059-69. doi:10.1093/brain/awl031
52. Teo JT, Edwards MJ, Bhatia K. Tardive dyskinesia is caused by maladaptive synaptic plasticity: a hypothesis. Mov Disord (2012) 27:1205-15. doi:10.1002/ mds. 25107

53. Hershey T, Black KJ, Carl JL, Mcgee-Minnich L, Snyder AZ, Perlmutter JS. Long term treatment and disease severity change brain responses to levodopa in Parkinson's disease. J Neurol Neurosurg Psychiatry (2003) 74:844-51. doi:10.1136/jnnp.74.7.844

54. Herz DM, Florin E, Christensen MS, Reck C, Barbe MT, Tscheuschler MK, et al. Dopamine replacement modulates oscillatory coupling between premotor and motor cortical areas in Parkinson's disease. Cereb Cortex (2013). doi:10.1093/cercor/bht140

55. Herz DM, Siebner HR, Hulme OJ, Florin E, Christensen MS, Timmermann L. Levodopa reinstates connectivity from prefrontal to premotor cortex during externally paced movement in Parkinson's disease. Neuroimage (2014) 90:15-23. doi:10.1016/j.neuroimage.2013.11.023

56. Barbier EL, Lamalle L, Decorps M. Methodology of brain perfusion imaging. $J$ Magn Reson Imaging (2001) 13:496-520. doi:10.1002/jmri.1073

57. Judenhofer MS, Wehrl HF, Newport DF, Catana C, Siegel SB, Becker M, et al. Simultaneous PET-MRI: a new approach for functional and morphological imaging. Nat Med (2008) 14:459-65. doi:10.1038/nm1700

58. Schlemmer HP, Pichler BJ, Schmand M, Burbar Z, Michel C, Ladebeck R, et al. Simultaneous MR/PET imaging of the human brain: feasibility study. Radiology (2008) 248:1028-35. doi:10.1148/radiol.2483071927

59. Wehrl HF, Hossain M, Lankes K, Liu CC, Bezrukov I, Martirosian P, et al. Simultaneous PET-MRI reveals brain function in activated and resting state on metabolic, hemodynamic and multiple temporal scales. Nat Med (2013) 19:1184-9. doi:10.1038/nm.3290

60. Cenci MA, Lee CS, Bjorklund A. L-DOPA-induced dyskinesia in the rat is associated with striatal overexpression of prodynorphin- and glutamic acid decarboxylase mRNA. Eur J Neurosci (1998) 10:2694-706. doi:10.1046/j.14609568.1998.00285.x

61. Cenci MA. Transcription factors involved in the pathogenesis of L-DOPAinduced dyskinesia in a rat model of Parkinson's disease. Amino Acids (2002) 23:105-9. doi:10.1007/s00726-001-0116-4

62. Lane E, Dunnett S. Animal models of Parkinson's disease and L-dopa induced dyskinesia: how close are we to the clinic? Psychopharmacology (Berl) (2008) 199:303-12. doi:10.1007/s00213-007-0931-8

63. Fox SH, Johnston TH, Li Q, Brotchie J, Bezard E. A critique of available scales and presentation of the Non-Human Primate Dyskinesia Rating Scale. Mov Disord (2012) 27:1373-8. doi:10.1002/mds.25133

64. Breger LS, Dunnett SB, Lane EL. Comparison of rating scales used to evaluate L-DOPA-induced dyskinesia in the 6-OHDA lesioned rat. Neurobiol Dis (2013) 50:142-50. doi:10.1016/j.nbd.2012.10.013

65. Clarke CE, Sambrook MA, Mitchell IJ, Crossman AR. Levodopa-induced dyskinesia and response fluctuations in primates rendered parkinsonian with 1-methyl-4-phenyl-1,2,3,6-tetrahydropyridine (MPTP). J Neurol Sci (1987) 78:273-80. doi:10.1016/0022-510X(87)90041-4

66. Calabresi P, Di Filippo M, Ghiglieri V, Tambasco N, Picconi B. Levodopainduced dyskinesias in patients with Parkinson's disease: filling the benchto-bedside gap. Lancet Neurol (2010) 9:1106-17. doi:10.1016/S1474-4422(10) 70218-0

67. Brotchie JM. Nondopaminergic mechanisms in levodopa-induced dyskinesia. Mov Disord (2005) 20:919-31. doi:10.1002/mds.20612

68. Santini E, Valjent E, Fisone G. Parkinson's disease: levodopa-induced dyskinesia and signal transduction. FEBS J (2008) 275:1392-9. doi:10.1111/j.17424658.2008.06296.x

69. Konradi C, Westin JE, Carta M, Eaton ME, Kuter K, Dekundy A, et al. Transcriptome analysis in a rat model of L-DOPA-induced dyskinesia. Neurobiol Dis (2004) 17:219-36. doi:10.1016/j.nbd.2004.07.005

70. Guigoni C, Doudnikoff E, Li Q, Bloch B, Bezard E. Altered D(1) dopamine receptor trafficking in parkinsonian and dyskinetic non-human primates. $\mathrm{Neu}$ robiol Dis (2007) 26:452-63. doi:10.1016/j.nbd.2007.02.001

71. Mela F, Marti M, Bido S, Cenci MA, Morari M. In vivo evidence for a differential contribution of striatal and nigral D1 and D2 receptors to L-DOPA induced dyskinesia and the accompanying surge of nigral amino acid levels. Neurobiol Dis (2012) 45:573-82. doi:10.1016/j.nbd.2011.09.015 
72. Fiorentini C, Savoia P, Savoldi D, Barbon A, Missale C. Persistent activation of the D1R/Shp-2/Erk1/2 pathway in 1-DOPA-induced dyskinesia in the 6hydroxy-dopamine rat model of Parkinson's disease. Neurobiol Dis (2013) 54:339-48. doi:10.1016/j.nbd.2013.01.005

73. Jenner P. Molecular mechanisms of L-DOPA-induced dyskinesia. Nat Rev Neurosci (2008) 9:665-77. doi:10.1038/nrn2471

74. Blanchet P, Bedard PJ, Britton DR, Kebabian JW. Differential effect of selective D-1 and D-2 dopamine receptor agonists on levodopa-induced dyskinesia in 1-methyl-4-phenyl-1,2,3,6-tetrahydropyridine-exposed monkeys. J Pharmacol Exp Ther (1993) 267:275-9.

75. Robelet S, Melon C, Guillet B, Salin P, Kerkerian-Le Goff L. Chronic L-DOPA treatment increases extracellular glutamate levels and GLT1 expression in the basal ganglia in a rat model of Parkinson's disease. Eur J Neurosci (2004) 20:1255-66. doi:10.1111/j.1460-9568.2004.03591.x

76. Nevalainen N, Lundblad M, Gerhardt GA, Stromberg I. Striatal glutamate release in L-DOPA-induced dyskinetic animals. PLoS One (2013) 8:e55706. doi:10.1371/journal.pone.0055706

77. Hallett PJ, Dunah AW, Ravenscroft P, Zhou S, Bezard E, Crossman AR, et al. Alterations of striatal NMDA receptor subunits associated with the development of dyskinesia in the MPTP-lesioned primate model of Parkinson's disease. Neuropharmacology (2005) 48:503-16. doi:10.1016/j.neuropharm.2004. 11.008

78. Samadi P, Gregoire L, Morissette M, Calon F, Hadj Tahar A, Dridi M, et al. mGluR5 metabotropic glutamate receptors and dyskinesias in MPTP monkeys. Neurobiol Aging (2008) 29:1040-51. doi:10.1016/j.neurobiolaging. 2007.02.005

79. Ouattara B, Hoyer D, Gregoire L, Morissette M, Gasparini F, Gomez-Mancilla $\mathrm{B}$, et al. Changes of AMPA receptors in MPTP monkeys with levodopa-induced dyskinesias. Neuroscience (2010) 167:1160-7. doi:10.1016/j.neuroscience.2010. 03.022

80. Ouattara B, Gregoire L, Morissette M, Gasparini F, Vranesic I, Bilbe G, et al. Metabotropic glutamate receptor type 5 in levodopa-induced motor complications. Neurobiol Aging (2011) 32:1286-95. doi:10.1016/j.neurobiolaging.2009. 07.014

81. Oh JD, Russell D, Vaughan CL, Chase TN. Enhanced tyrosine phosphorylation of striatal NMDA receptor subunits: effect of dopaminergic denervation and L-DOPA administration. Brain Res (1998) 813:150-9. doi:10.1016/S00068993(98)01049-X

82. Kong M, Ba M, Song L, Liu Z. Comparative effects of acute or chronic administration of levodopa to 6-OHDA-lesioned rats on the expression and phosphorylation of N-methyl-D-aspartate receptor NR1 subunits in the striatum. Neurochem Res (2009) 34:1513-21. doi:10.1007/s11064-0099939-2

83. Ba M, Kong M, Yu G, Sun X, Liu Z, Wang X. GluR1 phosphorylation and persistent expression of levodopa-induced motor response alterations in the hemiparkinsonian rat. Neurochem Res (2011) 36:1135-44. doi:10.1007/s11064-0110461-y

84. Gardoni F, Picconi B, Ghiglieri V, Polli F, Bagetta V, Bernardi G, et al. A critical interaction between NR2B and MAGUK in L-DOPA induced dyskinesia. J Neurosci (2006) 26:2914-22. doi:10.1523/JNEUROSCI.5326-05.2006

85. Silverdale MA, Kobylecki C, Hallett PJ, Li Q, Dunah AW, Ravenscroft P, et al. Synaptic recruitment of AMPA glutamate receptor subunits in levodopainduced dyskinesia in the MPTP-lesioned nonhuman primate. Synapse (2010) 64:177-80. doi:10.1002/syn.20739

86. Nishijima H, Arai A, Kimura T, Mori F, Yamada J, Migita K, et al. Drebrin immunoreactivity in the striatum of a rat model of levodopa-induced dyskinesia. Neuropathology (2013) 33:391-6. doi:10.1111/neup.12009

87. Ahmed I, Bose SK, Pavese N, Ramlackhansingh A, Turkheimer F, Hotton G, et al. Glutamate NMDA receptor dysregulation in Parkinson's disease with dyskinesias. Brain (2011) 134:979-86. doi:10.1093/brain/awr028

88. Calon F, Rajput AH, Hornykiewicz O, Bedard PJ, Di Paolo T. Levodopa-induced motor complications are associated with alterations of glutamate receptors in Parkinson's disease. Neurobiol Dis (2003) 14:404-16. doi:10.1016/j.nbd.2003. 07.003

89. Santiago M, Matarredona ER, Machado A, Cano J. Influence of serotoninergic drugs on in vivo dopamine extracellular output in rat striatum. $J \mathrm{Neu}$ rosci Res (1998) 52:591-8. doi:10.1002/(SICI)1097-4547(19980601)52:5<591: :AID-JNR11L>3.0.CO;2-5
90. Halje P, Tamte M, Richter U, Mohammed M, Cenci MA, Petersson P. Levodopa-induced dyskinesia is strongly associated with resonant cortical oscillations. J Neurosci (2012) 32:16541-51. doi:10.1523/JNEUROSCI.304712.2012

91. Hurley MJ, Mash DC, Jenner P. Dopamine D1 receptor expression in human basal ganglia and changes in Parkinson's disease. Mol Brain Res (2001) 87:271-9. doi:10.1016/S0169-328X(01)00022-5

92. Aubert I, Guigoni C, Hakansson K, Li Q, Dovero S, Barthe N, et al. Increased D1 dopamine receptor signaling in levodopa-induced dyskinesia. Ann Neurol (2005) 57:17-26. doi:10.1002/ana.20296

93. Bezard E, Gross CE, Qin L, Gurevich VV, Benovic JL, Gurevich EV. L-DOPA reverses the MPTP-induced elevation of the arrestin2 and GRK6 expression and enhanced ERK activation in monkey brain. Neurobiol Dis (2005) 18:323-35. doi:10.1016/j.nbd.2004.10.005

94. Neve KA, Seamans JK, Trantham-Davidson H. Dopamine receptor signaling. J Recept Signal Transduct Res (2004) 24:165-205.

95. Nicholas AP, Lubin FD, Hallett PJ, Vattem P, Ravenscroft P, Bezard E, et al. Striatal histone modifications in models of levodopa-induced dyskinesia. $J$ Neurochem (2008) 106:486-94. doi:10.1111/j.1471-4159.2008.05417.x

96. Santini E, Alcacer C, Cacciatore S, Heiman M, Herve D, Greengard P, et al. LDOPA activates ERK signaling and phosphorylates histone $\mathrm{H} 3$ in the striatonigral medium spiny neurons of hemiparkinsonian mice. J Neurochem (2009) 108:621-33. doi:10.1111/j.1471-4159.2008.05831.x

97. Andersson M, Konradi C, Cenci MA. cAMP response element-binding protein is required for dopamine-dependent gene expression in the intact but not the dopamine-denervated striatum. J Neurosci (2001) 21:9930-43.

98. Oh JD, Vaughan CL, Chase TN. Effect of dopamine denervation and dopamine agonist administration on serine phosphorylation of striatal NMDA receptor subunits. Brain Res (1999) 821:433-42. doi:10.1016/S0006-8993(99)01121-X

99. Conn PJ, Battaglia G, Marino MJ, Nicoletti F. Metabotropic glutamate receptors in the basal ganglia motor circuit. Nat Rev Neurosci (2005) 6:787-98. doi:10.1038/nrn 1763

100. Fiorentini C, Busi C, Spano P, Missale C. Role of receptor heterodimers in the development of L-dopa-induced dyskinesias in the 6-hydroxydopamine rat model of Parkinson's disease. Parkinsonism Relat Disord (2008) 14:S159-64. doi:10.1016/j.parkreldis.2008.04.022

101. Tang F-M, Sun Y-F, Wang R, Ding Y-M, Zhang G-Y, Jin G-Z. Dopamineglutamate interaction in rat striatal slices: changes of CCDPK II, PKA and LDH activity by receptor-mediated mechanisms. Acta Pharmacol Sin (2000) 21:145-50.

102. Voulalas PJ, Holtzclaw L, Wolstenholme J, Russell JT, Hyman SE. Metabotropic glutamate receptors and dopamine receptors cooperate to enhance extracellular signal-regulated kinase phosphorylation in striatal neurons. J Neurosci (2005) 25:3763-73. doi:10.1523/JNEUROSCI.4574-04.2005

103. Picconi B, Centonze D, Hakansson K, Bernardi G, Greengard P, Fisone G, et al. Loss of bidirectional striatal synaptic plasticity in L-DOPA-induced dyskinesia. Nat Neurosci (2003) 6:501-6. doi:10.1038/nn1040

104. Riahi G, Morissette M, Levesque D, Rouillard C, Samadi P, Parent M, et al. Effect of chronic l-DOPA treatment on 5-HT(1A) receptors in parkinsonian monkey brain. Neurochem Int (2012) 61:1160-71. doi:10.1016/j.neuint.2012. 08.009

105. Riahi G, Morissette M, Samadi P, Parent M, Di Paolo T. Basal ganglia serotonin $1 \mathrm{~B}$ receptors in parkinsonian monkeys with L-DOPA-induced dyskinesia. Biochem Pharmacol (2013) 86:970-8. doi:10.1016/j.bcp.2013.08.005

106. Rylander D, Parent M, O’Sullivan SS, Dovero S, Lees AJ, Bezard E, et al. Maladaptive plasticity of serotonin axon terminals in levodopa-induced dyskinesia. Ann Neurol (2010) 68:619-28. doi:10.1002/ana.22097

107. Zeng BY, Iravani MM, Jackson MJ, Rose S, Parent A, Jenner P. Morphological changes in serotoninergic neurites in the striatum and globus pallidus in levodopa primed MPTP treated common marmosets with dyskinesia. Neurobiol Dis (2010) 40:599-607. doi:10.1016/j.nbd.2010.08.004

108. Antonelli T, Fuxe K, Tomasini MC, Bartoszyk GD, Seyfried CA, Tanganelli S, et al. Effects of sarizotan on the corticostriatal glutamate pathways. Synapse (2005) 58:193-9. doi:10.1002/syn.20195

109. Dupre KB, Ostock CY, Eskow Jaunarajs KL, Button T, Savage LM, Wolf W, et al. Local modulation of striatal glutamate efflux by serotonin 1A receptor stimulation in dyskinetic, hemiparkinsonian rats. Exp Neurol (2011) 229:288-99. doi:10.1016/j.expneurol.2011.02.012 
110. Carta M, Carlsson T, Kirik D, Bjorklund A. Dopamine released from 5-HT terminals is the cause of L-DOPA-induced dyskinesia in parkinsonian rats. Brain (2007) 130:1819-33. doi:10.1093/brain/awm082

111. Gubellini P, Picconi B, Bari M, Battista N, Calabresi P, Centonze D, et al. Experimental parkinsonism alters endocannabinoid degradation: implications for striatal glutamatergic transmission. J Neurosci (2002) 22:6900-7.

112. Kofalvi A, Rodrigues RJ, Ledent C, Mackie K, Vizi ES, Cunha RA, et al. Involvement of cannabinoid receptors in the regulation of neurotransmitter release in the rodent striatum: a combined immunochemical and pharmacological analysis. J Neurosci (2005) 25:2874-84. doi:10.1523/JNEUROSCI.4232-04.2005

113. Meschler JP, Howlett AC. Signal transduction interactions between CB1 cannabinoid and dopamine receptors in the rat and monkey striatum. Neuropharmacology (2001) 40:918-26. doi:10.1016/S0028-3908(01)00012-0

114. Martin AB, Fernandez-Espejo E, Ferrer B, Gorriti MA, Bilbao A, Navarro $M$, et al. Expression and function of $\mathrm{CB1}$ receptor in the rat striatum: localization and effects on D1 and D2 dopamine receptor-mediated motor behaviors. Neuropsychopharmacology (2008) 33:1667-79. doi:10.1038/sj.npp. 1301558

115. Martinez A, Macheda T, Morgese MG, Trabace L, Giuffrida A. The cannabinoid agonist WIN55212-2 decreases L-DOPA-induced PKA activation and dyskinetic behavior in 6-OHDA-treated rats. Neurosci Res (2012) 72:236-42. doi:10.1016/j.neures.2011.12.006

116. Bonifati V, Fabrizio E, Cipriani R, Vanacore N, Meco G. Buspirone in levodopainduced dyskinesias. Clin Neuropharmacol (1994) 17:73-82. doi:10.1097/ 00002826-199402000-00008

117. Bibbiani F, Oh JD, Chase TN. Serotonin 5-HT1A agonist improves motor complications in rodent and primate parkinsonian models. Neurology (2001) 57:1829-34. doi:10.1212/WNL.57.10.1829

118. Iravani MM, Tayarani-Binazir K, Chu WB, Jackson MJ, Jenner P. In 1methyl-4-phenyl-1,2,3,6-tetrahydropyridine-treated primates, the selective 5hydroxytryptamine la agonist (R)-(+)-8-OHDPAT inhibits levodopa-induced dyskinesia but only with increased motor disability. J Pharmacol Exp Ther (2006) 319:1225-34. doi:10.1124/jpet.106.110429

119. Munoz A, Li Q, Gardoni F, Marcello E, Qin C, Carlsson T, et al. Combined 5-HT1A and 5-HT1B receptor agonists for the treatment of L-DOPA-induced dyskinesia. Brain (2008) 131:3380-94. doi:10.1093/brain/awn235

120. Bezard E, Tronci E, Pioli EY, Li Q, Porras G, Bjorklund A, et al. Study of the antidyskinetic effect of eltoprazine in animal models of levodopa-induced dyskinesia. Mov Disord (2013) 28:1088-96. doi:10.1002/mds.25366

121. Sieradzan KA, Fox SH, Hill M, Dick JPR, Crossman AR, Brotchie JM. Cannabinoids reduce levodopa-induced dyskinesia in Parkinson's disease: a pilot study. Neurology (2001) 57:2108-11. doi:10.1212/WNL.57.11.2108

122. Fox SH, Henry B, Hill M, Crossman A, Brotchie J. Stimulation of cannabinoid receptors reduces levodopa-induced dyskinesia in the MPTP-lesioned nonhuman primate model of Parkinson's disease. Mov Disord (2002) 17:1180-7. doi:10.1002/mds.10289

123. Morgese MG, Cassano T, Cuomo V, Giuffrida A. Anti-dyskinetic effects of cannabinoids in a rat model of Parkinson's disease: role of $\mathrm{CB}(1)$ and TRPV1 receptors. Exp Neurol (2007) 208:110-9. doi:10.1016/j.expneurol.2007. 07.021

124. Walsh S, Gorman AM, Finn DP, Dowd E. The effects of cannabinoid drugs on abnormal involuntary movements in dyskinetic and non-dyskinetic 6hydroxydopamine lesioned rats. Brain Res (2010) 1363:40-8. doi:10.1016/j. brainres.2010.09.086

125. Berg D, Godau J, Trenkwalder C, Eggert K, Csoti I, Storch A, et al. AFQ056 treatment of levodopa-induced dyskinesias: results of 2 randomized controlled trials. Mov Disord (2011) 26:1243-50. doi:10.1002/mds.23616

126. Kumar R, Hauser RA, Mostillo J, Dronamraju N, Graf A, Merschhemke M, et al. Mavoglurant (AFQ056) in combination with increased levodopa dosages in Parkinson's disease patients. Int J Neurosci (2013). doi:10.3109/00207454. 2013.841685

127. Maranis S, Stamatis D, Tsironis C, Konitsiotis S. Investigation of the antidyskinetic site of action of metabotropic and ionotropic glutamate receptor antagonists. Intracerebral infusions in 6-hydroxydopamine-lesioned rats with levodopa-induced dyskinesia. Eur J Pharmacol (2012) 683:71-7. doi:10.1016/ j.ejphar.2012.02.036

128. Marin C, Aguilar E, Rodriguez-Oroz MC, Bartoszyk GD, Obeso JA. Local administration of sarizotan into the subthalamic nucleus attenuates levodopa-induced dyskinesias in 6-OHDA-lesioned rats. Psychopharmacology (2009) 204:241-50. doi:10.1007/s00213-008-1452-9

129. Ostock CY, Dupre KB, Jaunarajs KL, Walters H, George J, Krolewski D, et al. Role of the primary motor cortex in L-DOPA-induced dyskinesia and its modulation by 5-HT1A receptor stimulation. Neuropharmacology (2011) 61:753-60. doi:10.1016/j.neuropharm.2011.05.021

130. Zhang X, Andren PE, Greengard P, Svenningsson P. Evidence for a role of the 5 -HT1B receptor and its adaptor protein, p11, in L-DOPA treatment of an animal model of Parkinsonism. Proc Natl Acad Sci USA (2008) 105:2163-8. doi:10.1073/pnas.0711839105

131. Jaunarajs KL, Dupre KB, Steiniger A, Klioueva A, Moore A, Kelly C, et al. Serotonin $1 \mathrm{~B}$ receptor stimulation reduces $\mathrm{D} 1$ receptor agonist-induced dyskinesia. Neuroreport (2009) 20:1265-9. doi:10.1097/WNR.0b013e3283300fd7

132. Stanford IM, Lacey MG. Differential actions of serotonin, mediated by $5-\mathrm{HT}_{1 \mathrm{~B}}$ and $5-\mathrm{HT}_{2 \mathrm{C}}$ receptors, on GABA-mediated synaptic input to rat substantia nigra pars reticulata neurons in vitro. J Neurosci (1996) 16:7566-73.

133. Johansson PA, Andersson M, Andersson KE, Cenci MA. Alterations in corti$\mathrm{cal}$ and basal ganglia levels of opioid receptor binding in a rat model of 1 DOPA-induced dyskinesia. Neurobiol Dis (2001) 8:220-39. doi:10.1006/nbdi. 2000.0372

134. Chen L, Togasaki DM, Langston JW, Di Monte DA, Quik M. Enhanced striatal opioid receptor-mediated G-protein activation in L-DOPA-treated dyskinetic monkeys. Neuroscience (2005) 132:409-20. doi:10.1016/j.neuroscience.2004. 10.026

135. Aubert I, Guigoni C, Li Q, Dovero S, Bioulac BH, Gross CE, et al. Enhanced preproenkephalin-B-derived opioid transmission in striatum and subthalamic nucleus converges upon globus pallidus internalis in L-3,4dihydroxyphenylalanine-induced dyskinesia. Biol Psychiatry (2007) 61:836-44. doi:10.1016/j.biopsych.2006.06.038

136. Ogura M, Kita H. Dynorphin exerts both postsynaptic and presynaptic effects in the globus pallidus of the rat. J Neurophysiol (2000) 83:3366-76.

137. Mabrouk OS, Marti M, Salvadori S, Morari M. The novel delta opioid receptor agonist UFP-512 dually modulates motor activity in hemiparkinsonian rats via control of the nigro-thalamic pathway. Neuroscience (2009) 164:360-9. doi:10.1016/j.neuroscience.2009.08.058

138. Henry B, Fox SH, Crossman AR, Brotchie JM. Mu- and delta-opioid receptor antagonists reduce levodopa-induced dyskinesia in the MPTP-lesioned primate model of Parkinson's disease. Exp Neurol (2001) 171:139-46. doi:10.1006/exnr. 2001.7727

139. Cox H, Togasaki DM, Chen L, Langston JW, Di Monte DA, Quik M. The selective kappa-opioid receptor agonist U50,488 reduces L-dopa-induced dyskinesias but worsens parkinsonism in MPTP-treated primates. Exp Neurol (2007) 205:101-7. doi:10.1016/j.expneurol.2007.01.024

140. Ikeda K, Yoshikawa S, Kurokawa T, Yuzawa N, Nakao K, Mochizuki H. TRK820 , a selective kappa opioid receptor agonist, could effectively ameliorate LDOPA-induced dyskinesia symptoms in a rat model of Parkinson's disease. Eur J Pharmacol (2009) 620:42-8. doi:10.1016/j.ejphar.2009.08.013

141. Koprich JB, Fox SH, Johnston TH, Goodman A, Le Bourdonnec B, Dolle $\mathrm{RE}$, et al. The selective mu-opioid receptor antagonist ADL5510 reduces levodopa-induced dyskinesia without affecting antiparkinsonian action in MPTP-lesioned macaque model of Parkinson's disease. Mov Disord (2011) 26:1225-33. doi:10.1002/mds.23631

142. Vernon AC, Natesan S, Modo M, Kapur S. Effect of chronic antipsychotic treatment on brain structure: a serial magnetic resonance imaging study with ex vivo and postmortem confirmation. Biol Psychiatry (2011) 69:936-44. doi:10.1016/j.biopsych.2010.11.010

143. Lettfuss NY, Fischer K, Sossi V, Pichler BJ, Von Ameln-Mayerhofer A. Imaging DA release in a rat model of L-DOPA-induced dyskinesias: a longitudinal in vivo PET investigation of the antidyskinetic effect of MDMA. Neuroimage (2012) 63:423-33. doi:10.1016/j.neuroimage.2012.06.051

144. Nahimi A, Holtzermann M, Landau AM, Simonsen M, Jakobsen S, Alstrup $\mathrm{AK}$, et al. Serotonergic modulation of receptor occupancy in rats treated with L-DOPA after unilateral 6-OHDA lesioning. J Neurochem (2012) 120:806-17. doi:10.1111/j.1471-4159.2011.07598.x

145. Ohlin KE, Sebastianutto I, Adkins CE, Lundblad C, Lockman PR, Cenci MA. Impact of L-DOPA treatment on regional cerebral blood flow and metabolism in the basal ganglia in a rat model of Parkinson's disease. Neuroimage (2012) 61:228-39. doi:10.1016/j.neuroimage.2012.02.066 
146. Dobrossy MD, Braun F, Klein S, Garcia J, Langen KJ, Weber WA, et al. [18F]desmethoxyfallypride as a novel PET radiotracer for quantitative in vivo dopamine D2/D3 receptor imaging in rat models of neurodegenerative diseases. Nucl Med Biol (2012) 39:1077-80. doi:10.1016/j.nucmedbio.2012. 04.003

Conflict of Interest Statement: The authors declare that the research was conducted in the absence of any commercial or financial relationships that could be construed as a potential conflict of interest.

Received: 01 May 2014; paper pending published: 15 May 2014; accepted: 29 May 2014; published online: 12 June 2014.
Citation: Finlay CJ, Duty S and Vernon AC (2014) Brain morphometry and the neurobiology of levodopa-induced dyskinesias: current knowledge and future potential for translational pre-clinical neuroimaging studies. Front. Neurol. 5:95. doi: 10.3389/fneur.2014.00095

This article was submitted to Movement Disorders, a section of the journal Frontiers in Neurology.

Copyright (c) 2014 Finlay, Duty and Vernon. This is an open-access article distributed under the terms of the Creative Commons Attribution License (CC BY). The use, distribution or reproduction in other forums is permitted, provided the original author(s) or licensor are credited and that the original publication in this journal is cited, in accordance with accepted academic practice. No use, distribution or reproduction is permitted which does not comply with these terms. 